\title{
Pattern of Malocclusion in Patients Attended in Orthodontic Department of a Tertiary Level Hospital
}

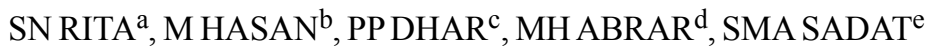

\begin{abstract}
Summary:
The aim of this study was to determine the pattern of individual traits of malocclusion, including sagittal molar relationship, overbite, overjet, crowding, spacing, cross bite, missing tooth, impacted tooth and extra tooth of upper and lower jaws in patients attended in Orthodontic Department of a Tertiary Level Hospital.
\end{abstract}

This cross-sectional study included orthodontic patients who visited the department of Orthodontics and Dentofacial Orthopedics in Sapporo Dental College and Hospital from January 2013 to February 2018.

Among the study population comprised of 371 patients the females were $57.1 \%$ and the males were $42.1 \%$.Among

Introduction:

The importance of beauty and attractiveness in today's society has been well established. Physically attractive people are perceived to be more kind, sensitive, interesting, strong, poised, modest, sociable, outgoing, exciting and responsive ${ }^{1}$.

People with a normal dental appearance are judged more socially attractive over many personal characteristics than those with malocclusions. In fact malocclusion is not an illness but an occlusal condition that lies within the boundaries of all possible occlusal discrepancies.

Occlusion is the relationship among all the components of masticatory system in their

a. Professor Dr. Sufia Nasrin Rita, Head, Dept. of Orthodontics, Sapporo Dental College

b. Dr. Mahdee Hasan, Senior Lecturer, Dept. of Orthodontics, Sapporo Dental College

c. Dr. Partha Protim Dhar, Senior Lecturer, Dept. of Orthodontics, Sapporo Dental College

d. Dr. Maruf Hossain Abrar, Assistant Professor, Dept. of Orthodontics, Sapporo Dental College

e. Dr. S. M. Anwar Sadat, Associate Professor \& Head, Dept. of Oral \& Maxillofacial Surgery, Sher-e-Bangla Medical College

Address of Correspondence: Professor Dr. Sufia Nasrin Rita. BDS, FCPS (Orthodontics and Dentofacial Orthopedics), Head, Dept. of Orthodontics, Sapporo Dental College. Email: sufianasrin2007@gmail.com, Cell:+8801711985427

Received: 25 May, 2018

Accepted: 7 March, 2019 them, $6.7 \%$ belonged to 6 to 11 years, $20.5 \%$ belonged to 12

to 17 years and the remaining $72.8 \%$ were of 18 -35 years of age. Angles Class I malocclusion was seen to be the most prevalent (64.2\%). In incisor classification, Class I malocclusion was seen to be the most prevalent (38.3\%). Increase in overjet, deep overbite, crossbite, crowding and spacing were found in $35.34 \%, 40.3 \%, 24.3 \%, 58.2 \%$ and $38.5 \%$ of the patients respectively.

Key Words: Crowding, Malocclusion, Orthodontics

(J Bangladesh Coll Phys Surg 2019; 37: 119-123)

DOI: https://doi.org/10.3329/jbcps.v37i3.41733

function, parafunction and dysfunction. ${ }^{2}$ Edward $\mathrm{H}$. Angle defined occlusion as a normal relationof occlusal inclined planes of the teeth when jaws are closed. ${ }^{3}$ Whereas, occlusion which isaesthetically and functionally not acceptable is referred to as malocclusion. ${ }^{2}$

The demand of orthodontic treatment is increasing as patients are more concerned about their esthetics. Therefore, the epidemiological data on the pattern of malocclusion is essential in assessing the resources required for orthodontic services and can also provide valuable information regarding the etiology of malocclusion. ${ }^{4}$

Dental malocclusion is present in all societies but its pattern varies. There have been several studies investigating the pattern of various dentofacial characteristic ${ }^{5,6}$ but only a few have been conducted on an orthodontic population. ${ }^{7}$ Identifying occlusal problem, their incidence and the need of treatment can help to determine the appropriate manpower needed in orthodontics.

The aim of this study was, therefore, to determine the pattern of individual traits of malocclusion, including sagittal molar relationship, overbite, overjet, crowding, spacing, crossbite, missing tooth, impacted tooth and extra tooth of upper and lower jaws in a sample of Bangladeshi orthodontic patients. Furthermore, the data 
will be useful to compare those of other populations in future and also will be useful in planning the treatment needs to those patients attending the department of orthodontics in Sapporo Dental College.

\section{Materials and Methods:}

This cross-sectional study included orthodontic patients who visited the department of Orthodontics and Dentofacial Orthopedics in Sapporo Dental College from January 2013 to February 2018. Pretreatment orthodontic records of 371 patients fulfilling the selection criteria were obtained and used for this study.

Those patients with complete pre-treatment records and those undergoing orthodontic treatment were included in the study. The exclusion criteria included those patients who came to dental OPD just for consultation or had previously undergone orthodontic treatment.

All data were collected from the records and dental casts of orthodontic patients. Sagittal molar relationship were classified as Angle's class I malocclusion, Class II div 1, Class II div 2 malocclusion and Class III malocclusion. Patients with Class I malocclusion having crowding, spacing, abnormal overjet and overbite were also included under Class I malocclusion. Class I malocclusion was characterized as the mesio-buccal cusp of maxillary first permanent molar occluding in the anterior buccal groove of mandibular first permanent molar. Class II malocclusion was characterized as disto-buccal cusp of maxillary first permanent molar occluding in the buccal groove of the mandibular first permanent molar. Classs II division 1 malocclusion was characterized by proclined upper incisors with increased overjet and deep overbite. Class II division 2 malocclusion was characterized by retroclined maxillary central incisors and proclined maxillary lateral incisors or retroclined maxillary central and lateral incisors and proclined maxillary canines with increased overbite and decreased overjet. Class III malocclusion was characterized as mesio-buccal cusp of maxillary first permanent molar occluding in the interdental space between mandibular first and second molars. ${ }^{3}$

Overjet is the horizontal distance between palatal surface of maxillary incisors and labial sueface of mandibular incisors. Overjet between 2 to $3 \mathrm{~mm}$ were considered as normal and more than $3 \mathrm{~mm}$ were considered as increased and less than $2 \mathrm{~mm}$ was considered as decreased and edge to edge bite. Overbite is the vertical overlapping of mandibular incisors by maxillary incisors. Overbite between 2 to $3 \mathrm{~mm}$ was considered normal. Greater than $3 \mathrm{~mm}$ was considered increased and less than 2 was considered decreased overbite. ${ }^{8}$ Crossbite or negative overjet were used when maxillary teeth were palatal or lingual in position than mandibular teeth.

Space in upper and lower arches exceeding $2 \mathrm{~mm}$ was considered spacing. ${ }^{2,9}$ Crowding was recorded in upper arch and lower arch. Between 0-1 mm, no crowding was considered. ${ }^{10}$ Scissor bite was recorded when palatal cusp of maxillary posterior teeth occluded buccal to the buccal cusp of lower posterior teeth or vice versa. When extra tooth was present clinically or radiographically it was also recoeded. ${ }^{11}$

All statistical analyses were performed by using SPSS 20.0 version. Descriptive statistics were calculated for the pattern of malocclusion and occlusal characteristics.

\section{Results:}

The study showed that among the total 371 patients in this study, $57.1 \%$ female and $42.1 \%$ male patients were seeking orthodontic treatment as shown in Figure1. Regarding the age of the subjects, they were divided into three groups: Ages 6 to11 (children), 12 to 17 (adolescents) and 18 to 35 (adults). Among them, 6.7\% belonged to 6 to 11 years, $20.5 \%$ belonged to 12 to 17 years and the remaining $72.8 \%$ were of $18-35$ years of age (Figure 2). Angles Class I malocclusion was seen to be the most prevalent (64.2\%).Class II malocclusion was seen in $25.3 \%$ of the subjects and class III was seen in $10.5 \%$ of them (Figure $3 \& 4$ ). In incisor classification, Class I malocclusion was seen to be the most prevalent (38\%), Class II Division 1 malocclusion was $33 \%$, Class II division 2 malocclusion was $6 \%$ \& Class III malocclusion was seen in $23 \%$ of them (Figure 5).

In this study increased overjet was found in $35.34 \%$ of the patients. Deep overbite was found in $40.3 \%$ of the subjects. Crossbite was found in $24.3 \%$ of the patients. In $58.2 \%$ of the subjects, crowding was present. In $38.5 \%$ of the patients, spacing was seen (Table 1 and Figure 6). 


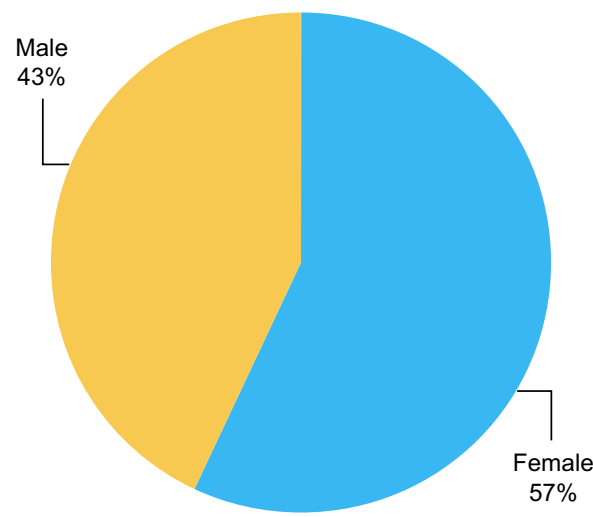

Fig.-1: Shows 57\% sample are female \& $43 \%$ are male.

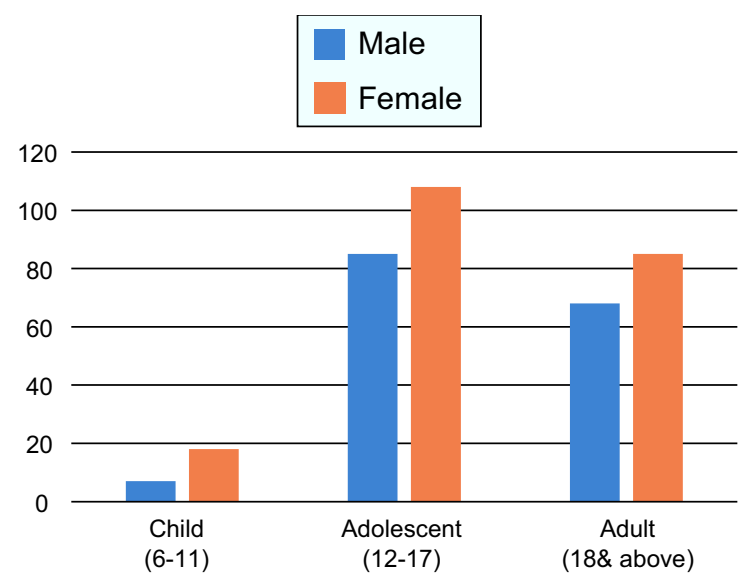

Fig.-2: shows adolescent patient are seeking more orthodontic treatment than other age group.

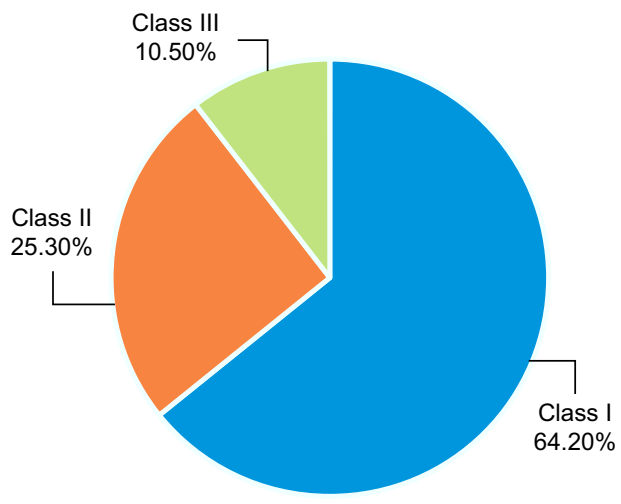

Fig.-3: shows Angle's Class I malocclusion is most common followed by Class II \& Class III

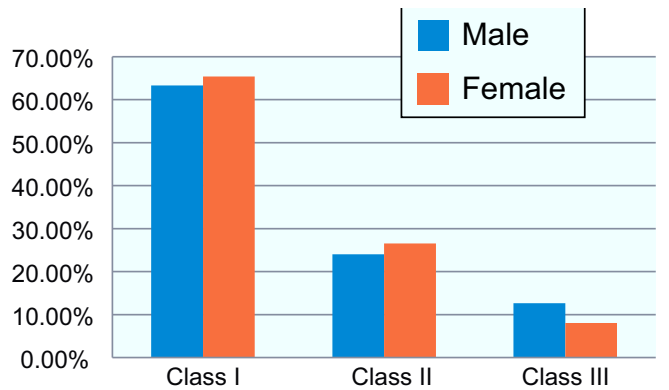

Fig.-4: shows Angle's Class I malocclusion is more than Class II \& III for both in male \& female

Variation of Angle classification among male \& female

\begin{tabular}{lccc}
\hline $\begin{array}{l}\text { Sex } \backslash \text { Angle } \\
\text { Classification }\end{array}$ & Class I & Class II & Class III \\
\hline M \%(n) & $63.30 \%(100)$ & $24.05 \%(38)$ & $12.65 \%(20)$ \\
F $\%(n)$ & $65.40 \%(138)$ & $26.55 \%(56)$ & $8.05 \%(17)$ \\
\hline
\end{tabular}

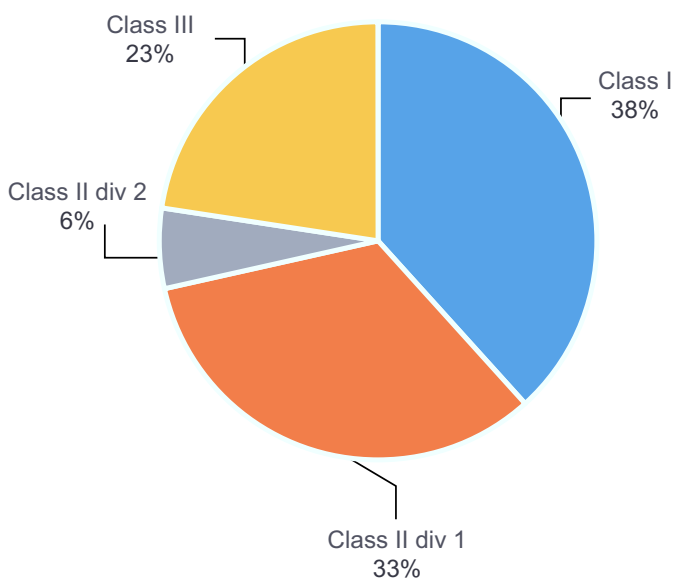

Fig.-5: Shows Class I \& Class II div-1 malocclusion are more common \& Class II div-2 is least common.

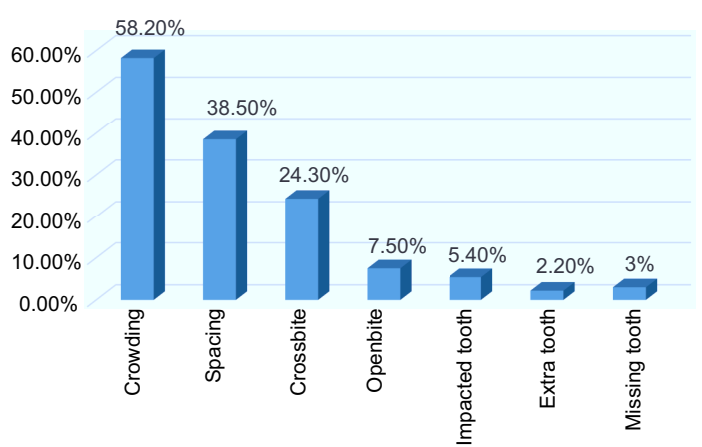

Fig.-6: Shows Crowding \& spacing are most causes for seeking orthodontic treatment. 
Table-I

\begin{tabular}{lccc}
\multicolumn{3}{c}{ Distribution of Overbite Overjet } \\
& Normal & Increased & Decreased \\
\hline Overjet & $53.16 \%$ & $35.34 \%$ & $11.49 \%$ \\
Overbite & $48.3 \%$ & $40.3 \%$ & $11.4 \%$ \\
\hline
\end{tabular}

\section{Discussion:}

In the present study, only those patients seeking orthodontic treatment were included. The present study demonstrated that Angle's Class I malocclusion was found in $64.2 \%$, Class II malocclusion was seen in $25.3 \%$ and class III malocclusion in $10.5 \%$. This result is almost similar to the study done by Rahman MM et al. ${ }^{12}$ in the Dhaka Dental College Hospital. It is also similar similar to the study conducted by Piya et al at Nepal Dental -Medical College. A study in Turkish population conducted by Sayin is differ from our study, where he found Class II malocclusion among patients was higher. The difference in sample size, ethnic variation and socio-demographic variations could be the reason for the differences.

Asian races showed a higher prevalence of Angle class III malocclusion than other races. ${ }^{13}$ Chinese and Malaysian adult males showed a much higher mean prevalence rate of Class III malocclusion whereas Indian males showed higher prevalence of Class II malocclusion which is inconsistent with the result of the present study. ${ }^{14}$

Gul-e- Erum and Fida done a study in Pakistani population \& found the prevalence of Class II malocclusion $(70.5 \%)$ and increased overjet $(75 \%)$ were higher followed by Class I and Class III malocclusion respectively. This could be due to difference in sample size and racial predisposition to certain malocclusion. In the study done by Albarakati and Sahar, ${ }^{15}$ Class I malocclusion was more prevalent in Saudi female population followed by Class III malocclusion while Class I malocclusion followed by Class II malocclusion was more prevalent in this study.

In incisor relationship, it was $38.3 \%$ Class I, $33.2 \%$ class II div $1,5.9 \%$ class II div $2 \& 22.6 \%$ class III. It is also very similar to the study conducted by Rahman MM et al. ${ }^{12}$
Among them females (59.5\%) were higher than males in seeking orthodontic treatment. This result is similar to the study done Rahman MM et al. This could be due to more esthetic concern in females than males regarding malocclusion or could be due to parental concern for matrimonial reasons.

Crowding was seen most prevalent in this study similar to other studies. ${ }^{8,15,16}$

In this study, Class I malocclusion was found to be more prevalent with no significant gender

differences which was concurrence with the study done in India. ${ }^{8}$ Similarly, no significant gender differences were obtained in case of crowding, overjet, overbite and spacing.

\section{Conclusion:}

In this hospital based study, the frequency of Class I, Class II and Class III malocclusion was found to be $59.5 \%, 26.7 \%$ and $13.7 \%$ respectively. Female were more concern \& seeking orthodontic treatment than male. Nationwide Survey including various ethnic groups of Bangladesh is necessary for proper planning of orthodontic treatment for the people of Bangladesh.

\section{References:}

1. Dionk K, Berscheid E, Walster E. What is beautiful is good . J Personality and social Psychology.1972;24:285-90.

2. Gul-E-Erum, Mubassar Fida. Pattern of malocclusion in orthodontic patients: A hospital based study. J Ayub Med Coll Abbottabad 2008;

3. Bhalajhi S.I. Orthodontics the art and science. $3^{\text {rd }}$ ed. March 2005: 55-56

4. Vab Kirk LEJr. Assesment of malocclusion in population groups. Am j public Health Nations Health. 1959; 49: 1157-63

5. Brunelle JA, Bhat M, Lipton JA. Prevalence and distribution of selected occlusal characteristics in the U. S. population, 198891. J dent Res 1996;75: 706-13

6. Profit WR, Field HW, Moray LJ. Prevalence of malocclusion and Orthodontic treatment need in the United States. Int J orthodon Orthognath surg 1998; 13: 97-106.

7. Jones BW. Malocclusion and facial types in a group of Saudi AArabian patients referred for orthodontic treatment: a preliminary study. Br J Orthod 1987; 14:143-6

8. Aniket H. Vibhute, Nupura A. Vibhute, Rajendra Daule, Prevalence of malocclusion characteristic and chief motivational factors for treatment in orthodontic patients from Maharashtra, India. Journal of Orthodontic Research May-Aug 2013: Vol 1 issue 2: 62-65. 
9. Mugonzibwa EA, Eskeli R, Laine-Alava MT, Kuijpers-Jagtman AM, Katsaros C. Spacing and crowding among African and Caucasian children. Orthod Craniofac Res 2008;11:82-89.

10. Gelgor IE, Karaman A, Ercan E. Prevalence of malocclusion among adolescents in Central Anatolia. Euro J Dent 2007; 1:125-31.

11. Dacosta O, Utomi L. Referral mode and pattern of malocclusion among patients attending the Lagos University Teaching Hospital, Lagos, Nigeria.O.S.T. T.D.J. Dec 2009: Vol. 32, No 4.

12. Rahman MM, Hossain Mz. Pattern of malocclusion in patient seeking orthodontic treatment at Dhaka Dental College\& hospital. Bangladesh journal of orthodontics \& dentofacial orthopaedics. April 2013, Vol 3 No 2: 9-11.
13. Daniel K. Hardy, Yltze P. Cubas, Maria F. Orellana. Prevalence of angle class III malocclusion: A systematic review and metaanalysis. Open Journal of Epidemiology, 2012, 2:75-82.

14. Jen Soh, Andrew Sandham, Yiong Huak Chan. Occlusal status in Asian male adults: prevalence and ethnic variation. Angle Orthodontist, 2005: Vol 75, No 5.

15. A Saharf, T Sahar. Malocclusion traits in Saudi females seeking orthodontic treatment. Pakistan Oral \& Dental Journal, June 2010: Vol 30, No. 1, 127.

16. Shrestha B.K, Yadav Rajiv, Basel Prem. Prevalence of malocclusion among high school students in Kathmandu Valley. Orthodontic Journal of Nepal, 2012; Vol. 2, No. 1:1-5 